\title{
UJI INKOMPATIBILITAS SOMATIK DAN PERTUMBUHAN JAMUR GANODERMA DARI KEBUN BENIH GENERASI PERTAMA Acacia auriculiformis DI WONOGIRI, JAWA TENGAH
}

Somatic Incompatibility and Growth of Ganoderma from Seed Orchard F1 Acacia auriculiformis at Wonogiri, Central Java

Siti Husna Nurrohmah dan Nur Hidayati

Balai Besar Penelitian Bioteknologi dan Pemuliaan Tanaman Hutan

J1. Palagan Tentara Pelajar Km 15, Purwobinangun, Pakem, Sleman, Yogyakarta 55582

e-mail: siti_husna_n@yahoo.com

\begin{abstract}
Seed orchard A. auriculiformis F1 at Wonogiri, Central Java has attacked by ganoderma caused root rot. To determine the genetic variation, the pattern of spread of ganoderma necessary to somatic incompatibility test and measure the growth. This study used 8 isolates of the fungus ganoderma. Fungi were grown on PDA (Potato dextrose agar), made parental isolates and paired with each other. The results showed that all pairings indicated incompatible reactions except self pairings. All self-pairings showed compatible reactions that indicated by miycelia merged on PDA forming a single colony. Incompatible reaction zone is characterized by sparse zone, demarcation line and pigmentation. The results of somatic incompatibility test, ganoderma have different genotypes or it is not a single colony. The result indicates that the distribution of root rot in Seed orchard A. auriculiformis F1 at Wonogiri, Central Java not only occured by root to root contact.
\end{abstract}

Keywords: somatic incompatibility, ganoderma, genetic variation, and acacia

\begin{abstract}
ABSTRAK
Kebun benih $A$. auriculiformis $\mathrm{F} 1$ di Wonogiri, Jawa Tengah telah terserang jamur ganoderma penyebab busuk akar. Untuk mengetahui variasi genetik, pola persebaran jamur ganoderma perlu dilakukan uji inkompatibilitas somatik dan pengukuran pertumbuhan. Dalam penelitian ini digunakan 8 isolat jamur ganoderma. Jamur ditumbuhkan pada media PDA (Potato dextrose agar), dibuat parental dan dipasangkan antara isolat yang satu dengan yang lainnya. Hasil penelitian menunjukkan seluruh pasangan menunjukkan reaksi inkompatibel kecuali pada pasangan sendiri. Pasangan sendiri menunjukkan reaksi kompatibel yang ditandai dengan bergabungnya miselia membentuk koloni tunggal. Reaksi inkompatibel ditandai dengan terbentuknya zona jarang, garis demarkasi, dan pembentukan pigmentasi. Hasil uji inkompatibiltas somatik menunjukkan bahwa jamur ganoderma memiliki genotip yang berbeda atau tidak berasal dari klon genetik yang sama. Hal ini mengindikasikan bahwa sebaran busuk akar di Kebun benih $A$. auriculiformis F1 di Wonogiri, Jawa Tengah terjadi tidak hanya melalui kontak akar.
\end{abstract}

Kata kunci: inkompatibilitas somatik, ganoderma, variasi genetik dan akasia 


\section{PENDAHULUAN}

Acacia auriculiformis merupakan salah satu jenis tanaman cepat tumbuh (fast growing species). Tanaman akasia banyak digunakan untuk memenuhi kebutuhan kayu sebagai bahan baku pulp, furniture, plywood, lantai, kontruksi ringan dan MDF (medium density fiberboard). Menurut Golani (2006) Indonesia termasuk salah satu negara penghasil pulp dan kertas di dunia. Sejalan dengan permintaan pasokan kayu Indonesia telah menetapkan progam pembangunan hutan tanaman yang luas. Pada tahun 2010 produksi kayu pulp di Indonesia mencapai 5.437.724 ton dan kayu lapis sebanyak 3.324.889 $\mathrm{m}^{3}$ (Bina Produksi Kehutanan, 2010).

Perubahan ekosistem dari hutan alam ke tanaman yang kebanyakan monokultur atau campuran dapat menyebabkan peningkatan serangan hama dan penyakit (Tri Waluyo dan Anggraini, 2000). Salah satu ancaman penyakit pada tanaman akasia adalah busuk akar yang disebabkan oleh jamur antara lain Ganoderma sp. Jamur ganoderma telah menyerang kebun benih generasi pertama baik $A$. mangium maupun A. auriculiformis di Wonogiri, Jawa Tengah. Jamur ganoderma termasuk kelompok basidiomycetes (Hood, 2006). Jamur ganoderma menyerang tanaman akasia dan menyebabkan penyakit busuk akar yang dapat menurunkan produktifitas bahkan menimbulkan kematian . Ganoderma sp mempunyai kisaran inang yang luas. Inokulum tumbuh dan menyebar di bawah permukaan tanah., sehingga inokulumnya akan bertahan pada akar dan stump (tunggul) pohon yang sudah mati. Inokulum inilah yang banyak menyerang tanaman di kemudian hari (Old et al., 2000).

Penyakit busuk akar dapat menyebar dengan melalui kontak akar tanaman yang sakit dengan akar tanaman yang sehat. Selain itu busuk akar memungkinkan tersebar melalui spora yang penyebarannya dibantu angin atau air. Spora tidak dapat menginfeksi tanaman sehat, tetapi dapat menginfeksi tonggak dari tanaman yang rentan, sehingga dapat menjadi sumber infeksi baru (Semangun, 1991). Pengamatan keragaman jamur ganoderma baik pertumbuhan maupun uji inkompatibilitas somatik diperlukan untuk melihat tipe sebaran jamur.

Inkompatibilitas somatik merupakan sistem untuk menjaga identitas individu (Lind et al., 2007). Menurut Worral 
(1997) inkompatibilitas somatik memiliki peran penting dalam konsep individual pada jamur. Inkompatibilitas somatik dalam basidiomycetes ditunjukkan dengan penolakan miselia yang berlainan genetik yang berfungsi untuk menjaga agar dalam suatu individu tidak terjadi perubahan genetik. Inkompatibilitas somatik mengatur penolakan dan pengakuan alelalel atau gen-gen yang sesuai dan tidak sesuai yang mengikuti pembentukan sel tubuh dalam sebuah kelompok organisme. Inkompatibilitas somatik merupakan proses pengenalan antara dua genotip yang tidak sama yang diikuti penolakan untuk membatasi sitoplasma dan mencegah terjadinya pertukaran genetik (Malik dan Vilgalys, 1999)

Studi tentang inkompatibilitas somatik dapat digunakan untuk mengetahui apakah jamur yang menyerang setiap pohon berasal dari klon jamur yang sama atau berbeda yang nantinya dapat digunakan untuk menganalisis populasi dan persebaran jamur di lapangan. Menurut Pilotti (2001), inkompatibilitas somatik dapat digunakan untuk menentukan isolat jamur memiliki genotip yang berbeda atau berasal dari klon genetik yang sama. Inkompatibilitas somatik banyak digunakan untuk mengidentifikasi strain dan mengamati keragaman genetik pada basidiomycetes (Fukuda et.al, 2003; Li et.al, 2011).

\section{BAHAN DAN METODE}

Bahan yang digunakan dalam penelitian ini adalah isolat jamur ganoderma yang berasal dari kebun benih generasi pertama A. auriculiformis di Wonogiri, Jawa tengah. Isolat jamur ganoderma diambil dari badan buah yang ditemukan pada $\operatorname{tanaman} A$. auriculiformis yang terkena penyakit busuk akar. Identitas pohon diperoleh berdasarkan Peta sebaran penyakit busuk akar di kebun benih F1, di Wonogri, Jawa Tengah. Adapun isolat yang digunakan sebanyak 8 isolat yaitu sebagai berikut:

Tabel 1. Daftar isolat jamur yang digunakan untuk uji inkompatibilitas somatik

\begin{tabular}{ccc}
\hline No & $\begin{array}{c}\text { Identitas isolat (asal } \\
\text { pohon) }\end{array}$ & $\begin{array}{c}\text { Kode } \\
\text { Pelabelan }\end{array}$ \\
\hline 1 & III $-53-2$ & A \\
2 & II $-121-1$ & B \\
3 & III $-87-1$ & C \\
4 & IV $-60-3$ & D \\
5 & IV $-54-3$ & E \\
6 & V $-51-2$ & F \\
7 & V $-64-3$ & G \\
8 & V $-32-3$ & H \\
\hline
\end{tabular}


Badan buah diambil dari tanaman A. auriculiformis yang terserang jamur ganoderma. Kemudian diisolasi dan di subkultur pada media PDA (Potato Dextrose Agar) dengan konsentrasi 11,2 gr dalam 300 ml aquades.

Selanjutnya untuk melakukan uji inkompatibilitas somatik dilakukan pembuatan initial plate agar isolat jamur mempunyai umur yang seragam dan pertumbuhan yang seragam dalam hal meristematis, viabilitas dan vigoritas. Dari initial plate dibuat isolat induk (parents culture) dan blok inokulum untuk pemasangan antar isolat. Isolat induk digunakan sebagai pembanding dari isolatisolat yang dipasangkan. Pembuatan blok inokulum diusahakan memunyai ukuran yang seragam dengan ukuran $\pm 3 \mathrm{~mm}^{2}$. Setiap pasangan isolat diletakkan pada media PDA dengan jarak $\pm 1-2 \mathrm{~mm}$ antar dua isolat. Pemasangan isolat dilakukan sedemikian rupa sehingga setiap isolat berpasangan dengan seluruh isolat yang dibuat dalam 3 ulangan (tabel 2).

Tabel 2. Pemasangan antar isolat jamur ganoderma yang berasal dari kebun benih F1 A. auriculiformis masing-masing dengan 3 ulangan

\begin{tabular}{rrrrrrrrrr}
\hline Isolat uji & $\begin{array}{c}\text { Kode } \\
\text { pelabelan }\end{array}$ & A & B & C & D & E & F & G & H \\
\hline III $-53-2$ & A & 3 & 3 & 3 & 3 & 3 & 3 & 3 & 3 \\
II $-121-1$ & B & & 3 & 3 & 3 & 3 & 3 & 3 & 3 \\
III $-87-1$ & C & & & 3 & 3 & 3 & 3 & 3 & 3 \\
IV $-60-3$ & D & & & 3 & 3 & 3 & 3 & 3 \\
IV $-54-3$ & E & & & & 3 & 3 & 3 & 3 \\
V $-51-2$ & F & & & & & 3 & 3 & 3 \\
V $-64-3$ & G & & & & & & 3 & 3 \\
V $-32-3$ & H & & & & & & & 3 \\
\hline
\end{tabular}

Selanjutnya setiap pasangan isolat diamati dan diukur pertumbuhannnya setiap 2 hari sekali dengan menghitung luas jamur menggunakan milimeter blok. Selain itu juga dihitung skoring pasangan yang menunjukkan reaksi inkompatibilitas.
Penilaian menggunakan angka 0-2 sebagai nilai derajat pertentangan antar isolat, yaitu $0=$ kompatibel (tidak terjadi reaksi), 1 = inkompatibel lemah (inkompatibel tanpa pigmentasi) dan $2=$ inkompatibel kuat (inkompatibel dengan pigmentasi) 
(Puspitasari dan Rimbawanto, 2010; Li et.al, 2011 ). Penilaian skoring diakukan setiap 2 hari sekali.

\section{HASIL DAN PEMBAHASAN}

Uji inkompatibilitas somatik jamur Ganoderma yang berasal dari Kebun benih A. auriculiformis $\mathrm{F} 1$, Wonogiri, Jawa Tengah dilakukan pada 8 isolat (A-H). Isolat-isolat yang ditumbuhkan pada media PDA (Potato Dextrose Agar) memiliki kenampakan morfologi yang hampir sama yaitu miselium berupa serabut halus berwarna putih, dan bagian tengah berwarna kuning (gambar 1). Menurut Seo dan Kirk (2000) Koloni pada ganoderma berwarna putih hingga kuning pucat. Warna kuning terbentuk di tengah kemudian menyebar secara radial. Miselium cenderung datar dan tidak menggumpal dan halus permukaannya. Beberapa kultur menunjukkan adanya hifa yang mengeras pada bagian tengah yang menyebar keluar yang biasa disebut sebagai crustose (Puspitasari dan Rimbawanto, 2010).

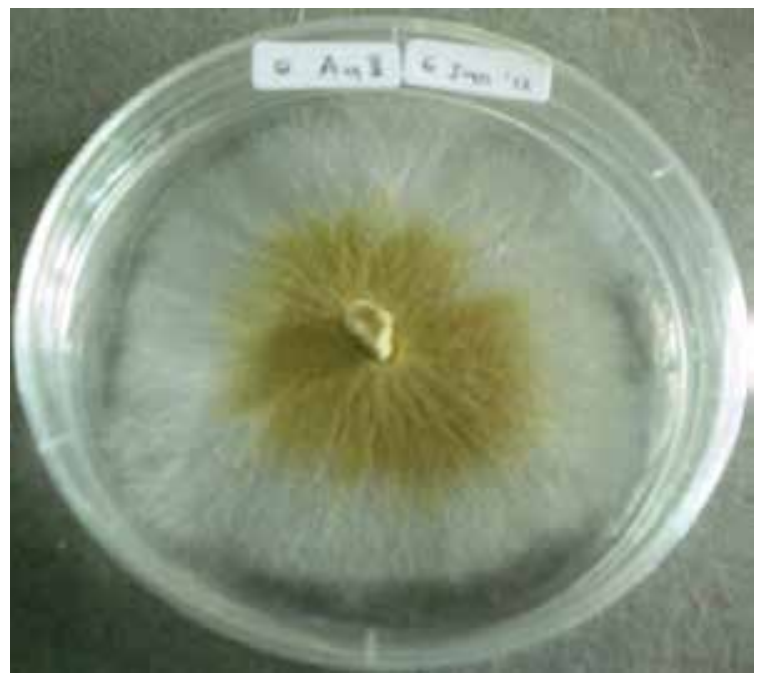

Gambar 1. Morfologi kultur jamur Ganoderma sp umur 10 hari

Hasil uji inkompatibilitas somatik menunjukkan adanya reaksi kompatibel dan inkompatibel (tabel 3).

Tabel 3. Hasil skoring uji inkompatibilitas somatik isolat Jamur Ganoderma sp yang berasal dari kebun benih $A$. auriculiformis $\mathrm{F} 1$, Wonogiri, Jawa Tengah

\begin{tabular}{cccccccccc}
\hline Isolat & $\begin{array}{c}\text { Kode } \\
\text { pelabelan }\end{array}$ & A & B & C & D & E & F & G & H \\
\hline III $-53-2$ & A & 0 & 1 & 1 & 1 & 1 & 2 & 2 & 1 \\
II $-121-1$ & B & & 0 & 2 & 1 & 2 & 2 & 1 & 2 \\
III $-87-1$ & C & & & 0 & 2 & 1 & 2 & 2 & 1 \\
IV $-60-3$ & D & & & 0 & 1 & 1 & 1 & 1 \\
IV $-54-3$ & E & & & & & 0 & 2 & 2 & 1 \\
V $-51-2$ & F & & & & & & 0 & 2 & 2 \\
V $-64-3$ & G & & & & & & & 0 & 2 \\
V $-32-3$ & H & & & & & & & \\
\hline
\end{tabular}

Ket. :

0 : kompatibel,

1 : inkompatibel lemah (inkompatibel tanpa pigmentasi)

2 : inkompatibel kuat (inkompatibel dengan pigmentasi) 
Reaksi kompatibel dan inkompatibel mulai nampak pada pasangan isolat-isolat ganoderma yang berumur 6 hari. Reaksi kompatibel ditunjukkan seluruh pasangan sendiri (self pairing) yaitu pasangan A-A, B-B, C-C, D-D, E-E, F-F, G-G, dan H-H.

Reaksi kompatibel yang nampak pada pasangan sendiri ini ditandai dengan miselium yang tampak menyatu dan tidak membentuk garis pemisah antara kedua miselium sehingga membentuk koloni tunggal (Gambar 2). Menurut Latifah dan Ho (2005) reaksi kompatibel pada pasangan sendiri ditunjukkan dengan bergabungnya miselia dari kedua isolat membentuk koloni tunggal. Miselia yang berasal dari pasangan sendiri menyatu dan tumbuh bersama membentuk koloni tunggal (Nusaibah et. al., 2010). Koloni tunggal

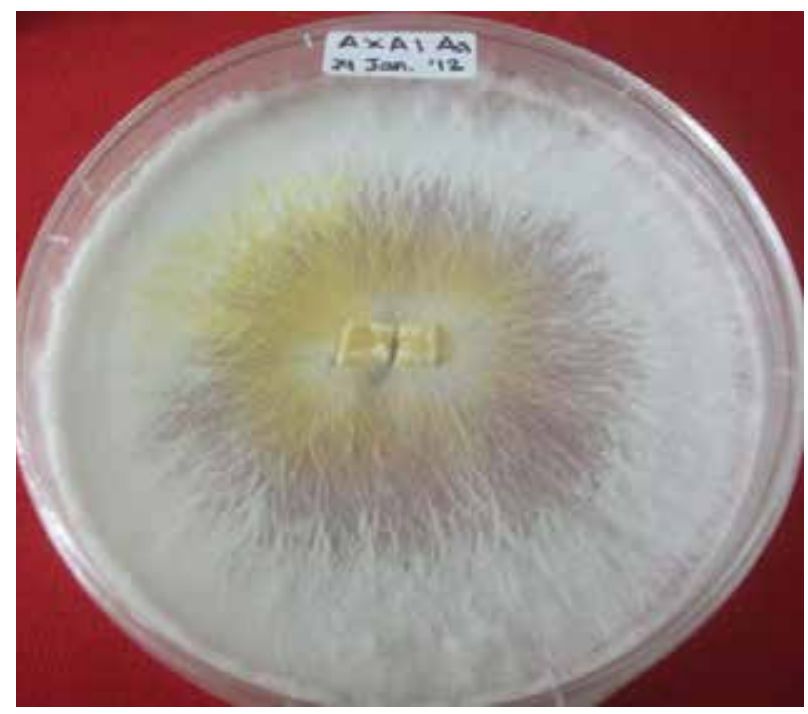

a tersebut terjadi karena miselia jamur saling bergabung dan mengalami anastomosis yaitu penggabungan dua hifa yang berbeda menjadi hifa dikaryotik yang diikuti dengan perpindahan isi hifa. Anastomosis pada hifa biasanya diikuti dengan terbentuknya struktur septal khusus pada miselia jamur yang disebut dengan clamp connection yang merupakan ciri khas pada golongan Basidiomycetes (Worral, 1997). Pada Tuber borchii, pasangan sendiri menunjukkan terjadinya penggabungan koloni dari dua isolat yang dipasangkan yang diikuti dengan pembauran hifa dan anastomosis. Selain itu pada pasangan sendiri Tuber borchii juga ditemukan hifa yang mengalami kekacauan (inter-mingling) tapi secara makroskopis tidak nampak reaksi inkompatibel pada zona interaksi (Sebrana et.al, 2007).

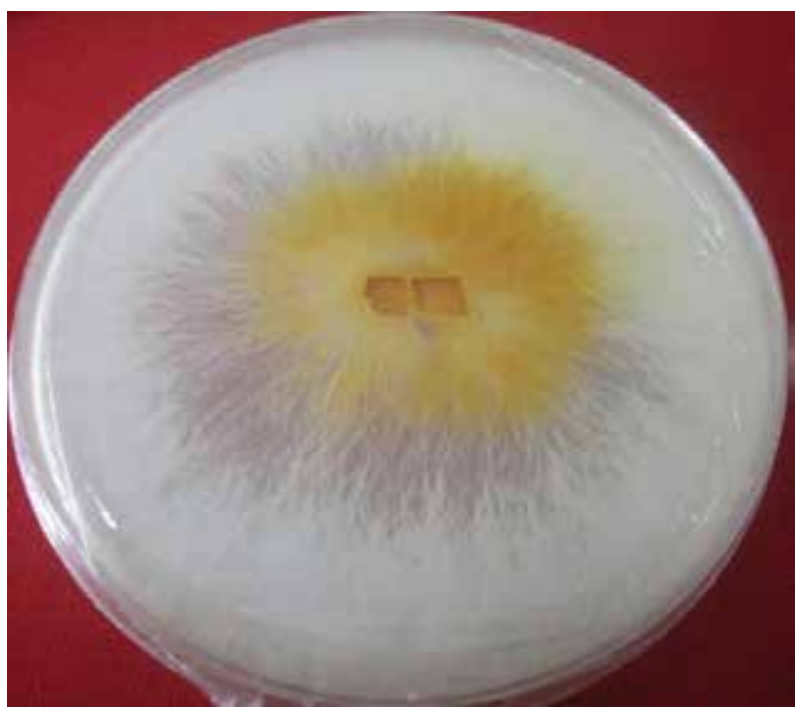

b

Gambar 2. Reaksi kompatibel pada pasangan sendiri (self pairing) A-A yang membentuk koloni tunggal yang ditandai dengan penyatuan miselia, tampak atas (a) dan tampak bawah (b) 
Pada gambar 2, tampak atas maupun tampak bawah, miselium dari dua isolat menyatu dan tumbuh bersama membentuk koloni tunggal. Pada persatuan kedua isolat pasangan sendiri tidak dtemukan garis batas , dinding, zona jarang maupun pigmentasi. Pada uji inkompatibilitas somatik Ganoderma boninense yang dilakukan oleh Nusaibah et. al (2010) juga menunjukkan reaksi kompatibel pada pasangan sendiri dan tidak ditemukan adanya garis batas pada pasangan sendiri. Menurut Suwandi et.al (2004) reaksi kompatibel ditandai dengan tidak terbentuknya zona jarang, miselia yang berasal dari kedua isolat tumbuh bersama dan bergabung menjadi koloni tunggal. Reaksi kompatibel biasanya ditunjukkan oleh pasangan isolat yang memiliki genotip

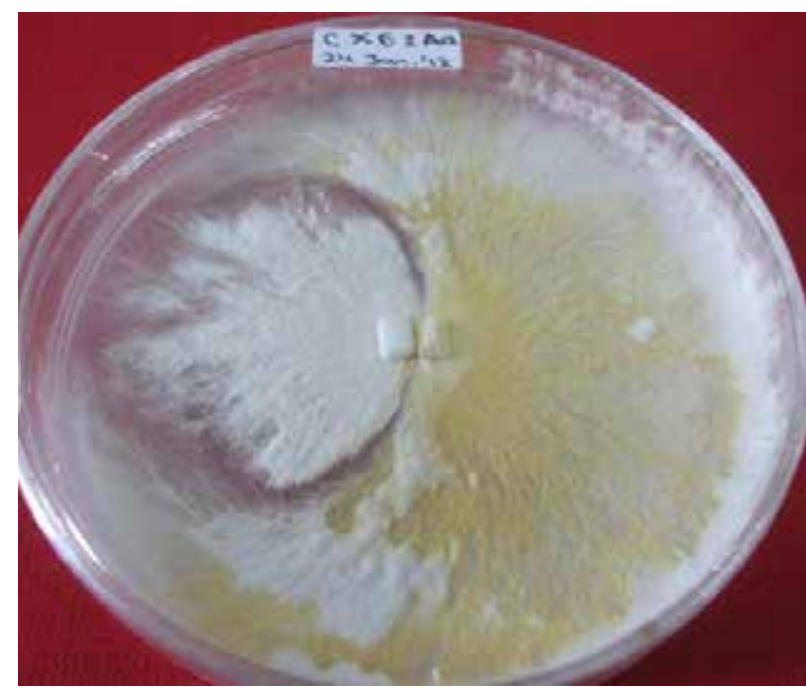

a yang sama atau identik (Worral, 1997 dan Suwandi et.al, 2004).

Reaksi inkompatibilitas somatik (reaksi ketidakcocokan somatik) ditemukan pada seluruh uji pasangan antara dua isolat yang berasal dari pohon berbeda. Reaksi inkompatibel ditunjukkan seluruh pasangan kecuali pada pasangan sendiri. Reaksi inkompatibel ditunjukkan dengan terbentuknya zona jarang dan terbentuknya dinding ataupun garis batas, Pada pasangan yang menunjukkan reaksi inkompatibel kuat dapat dijumpai terjadinya pigmentasi. Pembentukan zona jarang antar miselium jamur yang dipasangkan terdapat pada pasangan isolat A-B, A-C, A-E, A-F, A-G, A-H, B-C, B-E, B-F, B-G, B-H, C-E, E-F dan E-G (gambar 3).

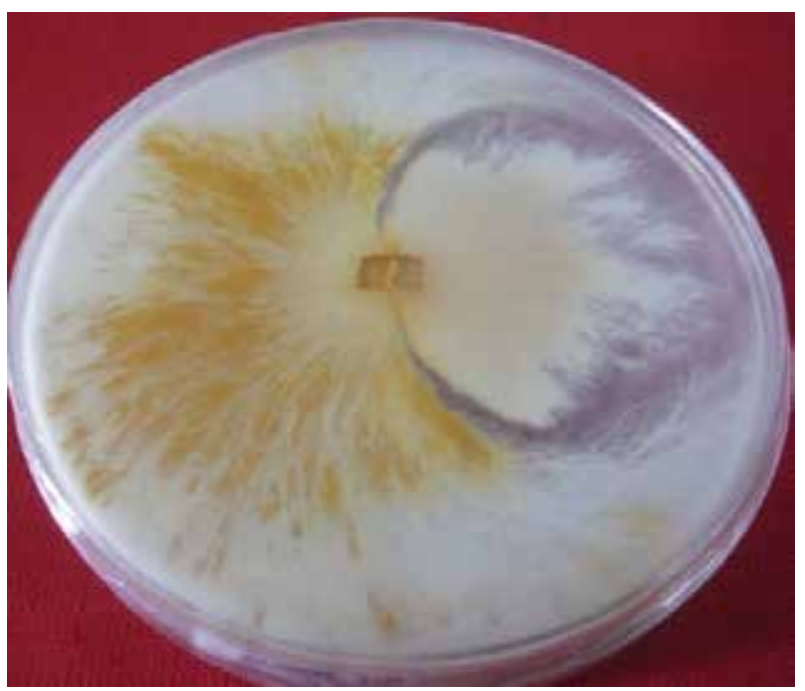

b

Gambar 3. Reaksi inkompatibel yang ditunjukkan dengan terbentuknya zona jarang tampak atas (a) dan tampak bawah (b) 
Pada gambar 3, tampak zona jarang yaitu daerah yang tidak atau jarang ditumbuhi miselia yang membatasi pertemuan kedua isolat. Reaksi inkompatibilitas juga ditunjukkan dengan adanya pembentukan garis demarkasi sebagai pembatas antara

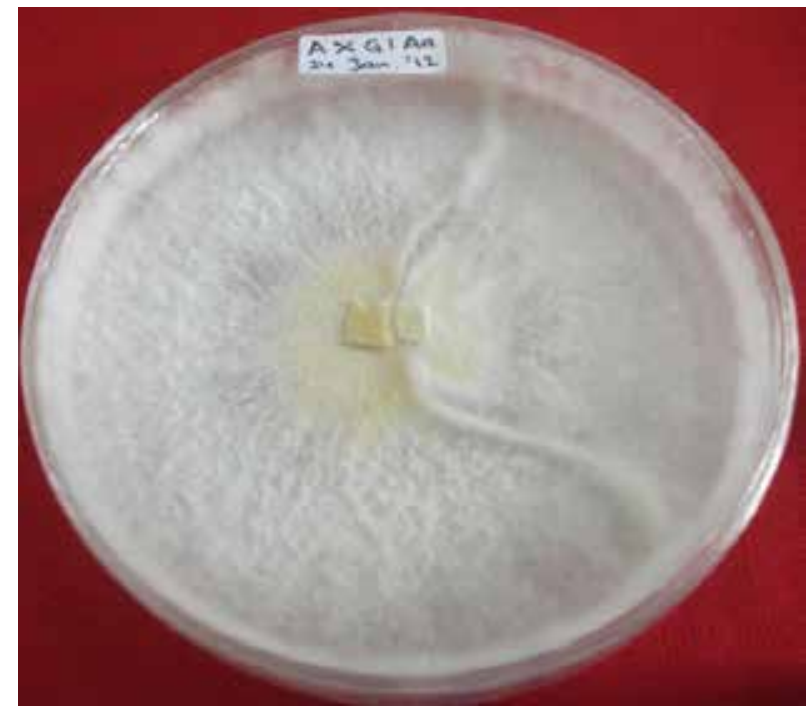

Gambar 4. Gambar 4. Dinding yang terbentuk pada pertemuan isolat yang inkompatibel, pasangan A-G (a) dan pasangan B-C (b)

Pada pembentukan garis demarkasi kadang-kadang juga dijumpai adanya pigmentasi. Pigmentasi mulai dapat dilihat pada umur 6 hari yang ditandai dengan adanya garis berwarna kuning kecoklatan pada pertemuan miselium jamur yang berubah menjadi coklat orange pada umur lanjut (Gambar 5). Pigmentasi ini berbeda dengan pembentukan crustose pada perkembangan lanjut isolat jamur Ganoderma sp. Pigmentasi dari reaksi inkompatibilitas

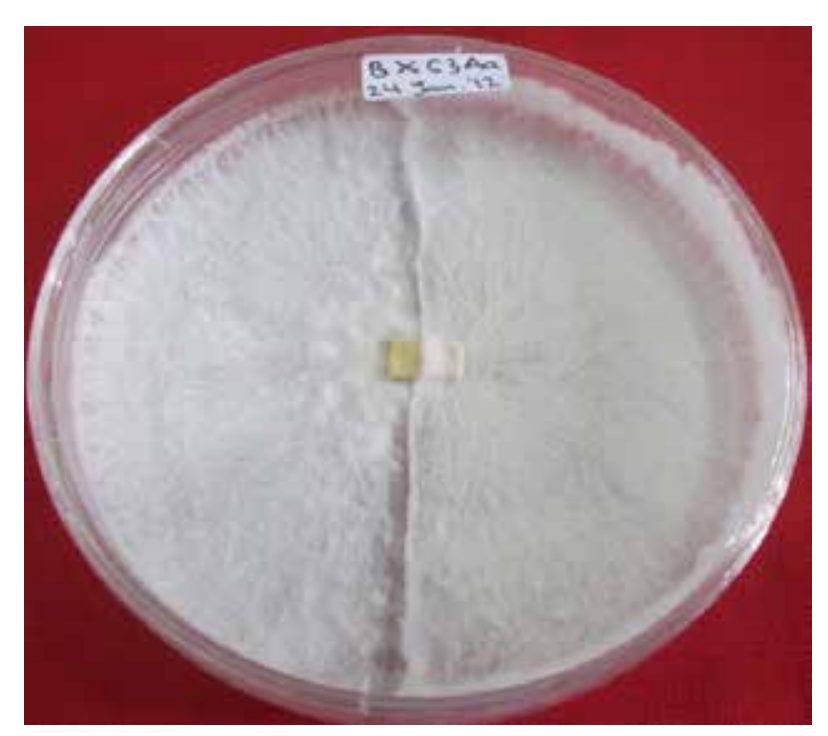

dua isolat. Batas tersebut dapat berupa dinding sclerotia yaitu pada pasangan isolat A-C, A-G, B-C, B-D, C-D, C-F, C-G, D-E, D-F, D-G, D-H, E-H, F-G, F-H dan G-H (gambar 4). 
kuat ditandai dengan adanya pigmentasi. Begitu pula Li et. al (2011) menjelaskan pada Auricularia auricula-judae dijumpai berbagai tipe reaksi, yaitu reaksi kompatibel dan reaksi inkompatibel. Reaksi kompatibel yang ditunjukkan dengan bergabungnya dua koloni sedangkan reaksi inkompatibel dibagi berdasarkan ada tidaknya pigmentasi pada pertemuan antara dua isolat. Menurut Sebrana et.al (2007) pasangan yang berasal dari dua isolat yang berbeda menunjukkan respon penolakan antara lain terhambatnya pertumbuhan hifa sehingga terbentuk zona pemisah dan dapat pula dikarenakan berkembangnya aerial myselium.

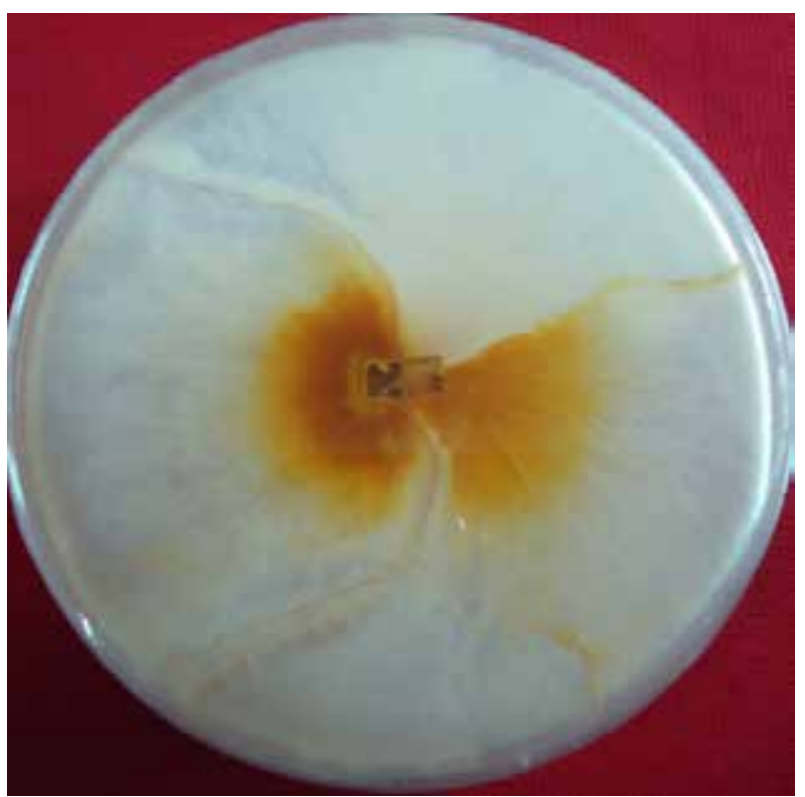

Gambar 5. Reaksi inkompatibel berupa pembentukan garis atau dinding yang disertai pembentukan pigmen berwarna kuning atau oranye tampak atas (a) dan kelihatan lebih jelas tampak bawah (b)

Guler (2008) menjelaskan bahwa pada reaksi inkompatibel, hifa membawa nuklei yang berbeda satu dengan lainnya dan tidak identik secara genetik yang akan membentuk koloni yang heterokaryotik. Dengan kata lain, anastomosis tidak akan terjadi pada pertemuan dua miselium dari dua isolat jamur yang tidak identik secara genetik. Anastomosis gagal dan tidak akan terjadi perubahan atau perpindahan nuklei dari miselium satu ke miselium lainnya (Puspitasari dan Rimbawanto, 2010). Menurut Worall (1997) bentuk garis demarkasi terbentuk pada hampir semua pasangan isolat yang mempunyai tipe miselia yang berbeda atau tidak identik 
secara genetik baik pada monosporous atau miselia sekunder. Pada garis batas pertemuan dua isolat yang inkompatibel, beberapa hifa mengalami degenerasi dan mati. Garis batas tersebut berfungsi untuk menghalangi terjadinya pertukaran sitoplasma dan nukleus. Pada reaksi inkompatibel terjadi kegagalan fusi, penolakan hifa bahkan kematian sel (Sebrana et.al, 2007). Pengenalan antara dua isolat yang genotipnya tidak identik, biasanya diikuti dengan respon penolakan antar masingmasing isolat untuk membatasi sitoplasma dan mencegah pertukaran nukleus (Malik dan Vilgalys, 1999). Menurut Pilotti (2001), inkompatibilitas somatik merupakan suatu sistem untuk menjaga identitas individu dengan cara mencegah pertukaran genetik.

Pada pasangan-pasangan yang menunjukkan reaksi inkompatibilitas yang ditandai pembentukan zona jarang, dinding dan pigmentasi, tampak pula perbedaan pertumbuhan antara isolat-isolat jamur ganoderma yang dipasangkan. Pertumbuhan jamur dapat dilihat dari kisaran luas jamur. Penghitungan luas jamur dilakukan saat kultur uji jamur Ganoderma sp berumur 6 hari. Hasil pengukuran pertumbuhan jamur ganoderma menunjukkan adanya perbedaan kecepatan tumbuh masing-masing isolat (gambar 6).

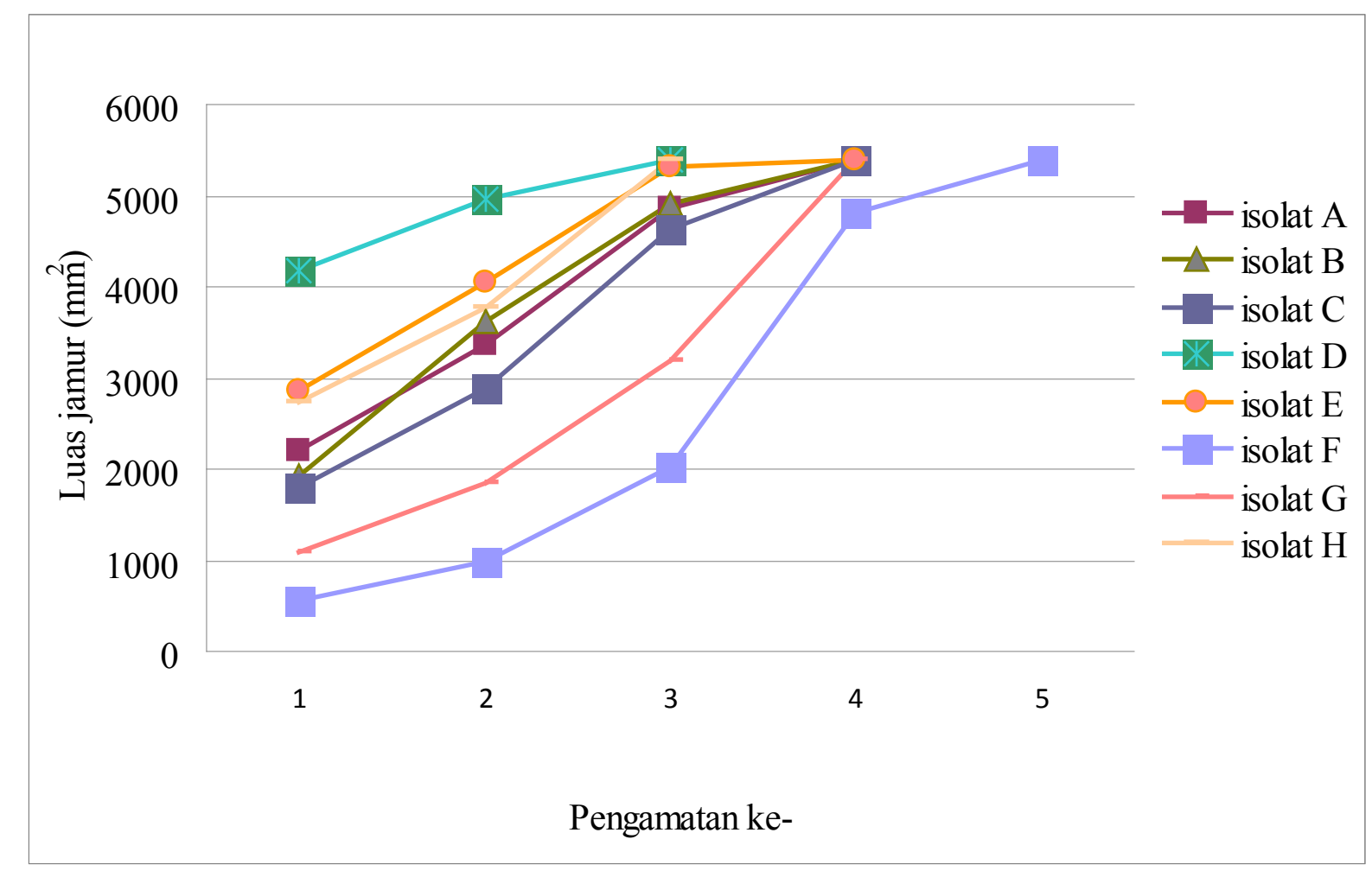

Gambar 6. Pertumbuhan isolat parental jamur Ganoderma sp 
Berdasarkan gambar 6, pertumbuhan isolat parental jamur ganoderma $\mathrm{sp}$ berbeda antar isolat. Pertumbuhan tercepat ditunjukkan parental plate isolat $\mathrm{D}$ dan $\mathrm{H}$ yang mencapai luas penuh pada umur kultur 10 hari, parental plate isolat $\mathrm{A}, \mathrm{B}, \mathrm{C}, \mathrm{E}$, dan $\mathrm{G}$, mencapai luas penuh pada umur kultur 12 hari, sedangkan parental plate isolat $\mathrm{F}$ mencapai luas penuh pada umur kultur 14 hari. Masing-masing isolat jamur mempunyai pola pertumbuhan yang berbeda dilihat dari pertambahan luas dari pengamatan pertama ke pengamatan kedua dan dari pengamatan kedua ke pengamatan ketiga dan seterusnya. Beberapa isolat mempunyai kecenderungan pola pertumbuhan dari lambat kemudian menjadi cepat, seperti pada isolat $A, C$, F, G, dan H. Laju pertumbuhan isolat $\mathrm{E}$ relatif sama, yaitu pertambahan luas dari pengamatan pertama ke pengamatan kedua dan dari pengamatan kedua ke pengamatan ketiga relatif sama. Sedangkan untuk isolat $\mathrm{B}$ dan $\mathrm{D}$ mempunyai kecenderungan pertumbuhan dari cepat ke lambat.

Perbedaan kecepatan tumbuh ini juga ditunjukkan oleh pasangan-pasangan isolat yang menunjukkan reaksi inkompatibel. Kedua isolat yang dipasangkan menunjukkan pertumbuhan yang berbeda, ada isolat yang tumbuh lebih cepat, ada pula yang lebih lambat. Perbedaan kecepatan tumbuh tersebut tampak sejak awal pertumbuhan (gambar 7a). Reaksi inkompatibel menunjukkan adanya penolakan miselia dan adanya persaingan pertumbuhan diantara kedua isolat. Menurut Worrall (1997) pada proses penolakan miselia akan diikuti dengan kompetisi dan invasi pertumbuhan. Pada gambar $7 \mathrm{~b}$ tampak kompetisi pertumbuhan antara dua isolat semakin terlihat jelas, isolat E tumbuh jauh lebih cepat sehingga isolat jamur $\mathrm{F}$ dikelilingi oleh miselia dari isolat jamur E. Pada reaksi inkompatibel dapat terjadi penghambatan pertumbuhan hifa dengan terpentuknya zona pemisah. Pada Tuber borchii juga dijumpai isolat yang menunjukkan kemampuan kompetisi yang lebih tinggi dari isolat lainnya (Sebrana et.al, 2007). 

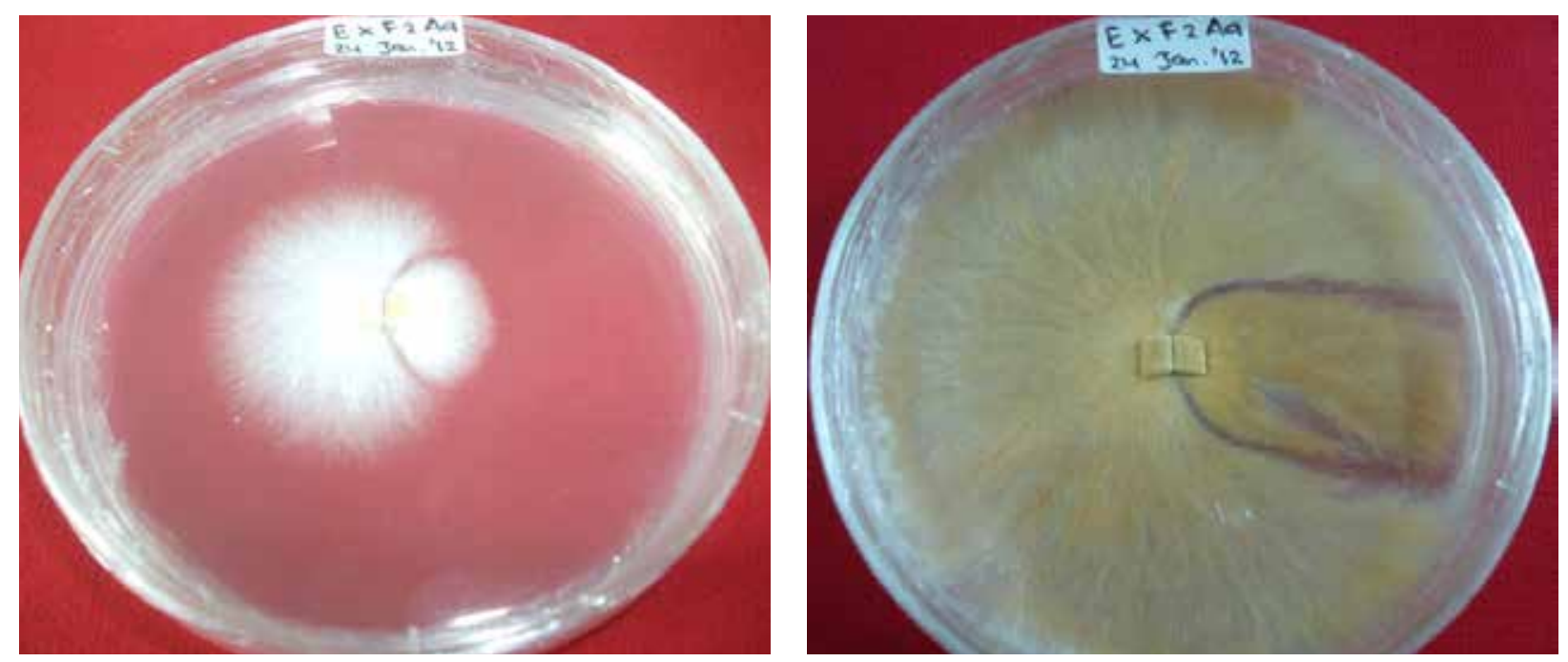

Gambar 7. Perbedaan kecepatan tumbuh (kompetisi pertumbuhan) pasangan isolat inkompatibel E-F pada awal pertumbuhan (7a) dan akhir pertumbuhan (7b)

\begin{tabular}{|c|c|c|c|c|c|c|c|c|c|c|c|c|c|c|c|c|c|c|c|c|c|c|c|c|}
\hline & 1 & 2 & 3 & 4 & 5 & 6 & 7 & 8 & 9 & 10 & 11 & 12 & 13 & 14 & 15 & 16 & 17 & 18 & 19 & 20 & 21 & 22 & 23 & 24 \\
\hline 1 & 0 & 0 & 0 & 99 & 110 & 75 & 12 & 45 & 129 & 98 & 6 & 66 & 55 & 23 & 25 & 9 & 31 & 19 & 120 & 22 & 30 & 108 & 45 & 0 \\
\hline 2 & 133 & 53 & 36 & 67 & 79 & 123 & 81 & 23 & 84 & 118 & 105 & 74 & 132 & 48 & 4 & 124 & 115 & 130 & 24 & 104 & 129 & 71 & 111 & 0 \\
\hline 3 & 50 & 73 & 102 & 61 & 109 & 82 & 46 & 97 & 83 & 32 & 30 & 115 & 92 & 12 & 62 & 131 & 118 & 128 & 58 & 80 & 38 & 74 & 75 & 0 \\
\hline 4 & 94 & 127 & 88 & 80 & 18 & 40 & 37 & 9 & 2 & 4 & 49 & 21 & 60 & 35 & 97 & 121 & 103 & 17 & 126 & 63 & 69 & 82 & 29 & 27 \\
\hline 5 & 93 & 120 & 27 & 13 & 90 & 117 & 34 & 138 & 22 & 8 & 137 & 52 & 67 & 43 & 113 & 14 & 102 & 64 & 123 & 16 & 114 & 7 & 3 & 61 \\
\hline 6 & 139 & 14 & 42 & 116 & 69 & 29 & 15 & 78 & 135 & 85 & 54 & 124 & 65 & 68 & 98 & 72 & 15 & 137 & 36 & 33 & 52 & 42 & 32 & 5 \\
\hline 7 & 16 & 31 & 25 & 62 & 68 & 112 & 130 & 38 & 7 & 51 & 71 & 96 & 139 & 1 & 26 & 84 & 135 & 59 & 39 & 28 & 100 & 44 & 105 & 93 \\
\hline 8 & 58 & 64 & 134 & 114 & 101 & 103 & 92 & 86 & 33 & 122 & 111 & 108 & 88 & 91 & 18 & 117 & 50 & 79 & 49 & 76 & 116 & 81 & 86 & 90 \\
\hline 9 & 28 & 113 & 44 & 60 & 126 & 19 & 47 & 87 & 35 & 24 & 55 & 3 & 134 & 78 & 73 & 66 & A & 133 & 101 & 99 & 70 & 77 & C & 8 \\
\hline 10 & 72 & 48 & 70 & 95 & 131 & 77 & 63 & 59 & 1 & 26 & 132 & 100 & 6 & 54 & 127 & 47 & 37 & 2 & 34 & 51 & 109 & 110 & 122 & 95 \\
\hline 11 & 65 & 76 & 39 & 17 & 104 & 43 & 121 & 91 & 5 & 128 & 107 & 41 & 40 & 94 & 107 & 13 & 41 & 83 & 85 & 21 & 46 & 96 & 138 & 112 \\
\hline 12 & 41 & 71 & 13 & 23 & 31 & 14 & 49 & 68 & 133 & 9 & 113 & 16 & D & 118 & 29 & 22 & 126 & 134 & 67 & 103 & 127 & 116 & 81 & 0 \\
\hline 13 & 24 & 88 & 48 & 91 & 62 & 64 & 112 & 99 & 66 & 7 & 77 & B & 42 & 3 & 80 & 38 & 32 & 114 & 84 & 128 & 66 & 14 & 83 & 0 \\
\hline 14 & 15 & 21 & 58 & 109 & 115 & 29 & 110 & 98 & 54 & 103 & 128 & 19 & 34 & 87 & 82 & 94 & 70 & 8 & 104 & 91 & 130 & 86 & 76 & 0 \\
\hline 15 & 78 & 127 & 12 & 83 & 100 & 55 & 135 & 95 & 116 & 17 & 130 & 40 & 48 & 35 & 26 & 108 & 100 & 79 & 109 & 88 & 59 & 74 & 65 & 7 \\
\hline 16 & 0 & 2 & 101 & 104 & 126 & 92 & 53 & 70 & 111 & 73 & 117 & 60 & 24 & 45 & 102 & 19 & 90 & 115 & 47 & 124 & 55 & 62 & 63 & 15 \\
\hline 17 & 0 & 5 & 38 & 6 & 35 & 4 & 45 & 122 & 102 & 51 & 107 & 1 & 5 & 139 & 52 & 49 & 137 & 78 & 36 & 46 & 64 & 121 & 122 & 4 \\
\hline 18 & 0 & 84 & 39 & 65 & 79 & 74 & 36 & 81 & 3 & 27 & 59 & 134 & 33 & 61 & 138 & 135 & 68 & 13 & 95 & 39 & 25 & 30 & 77 & 21 \\
\hline 19 & 0 & 52 & 75 & 22 & 132 & 30 & 33 & 61 & 93 & 97 & 86 & 85 & 53 & 23 & 2 & 117 & 120 & 12 & 93 & 44 & 110 & 98 & 101 & 111 \\
\hline 20 & 0 & 138 & 47 & 67 & 108 & 37 & 124 & 46 & 44 & 50 & 69 & 123 & 6 & 18 & 17 & 40 & $E$ & 123 & 50 & 31 & 131 & 71 & 37 & 105 \\
\hline 21 & 0 & 131 & 72 & 76 & 26 & 18 & 43 & 96 & 94 & 28 & 42 & 25 & 1 & 107 & 43 & 92 & 41 & 73 & 69 & 72 & 85 & 28 & 9 & 51 \\
\hline 22 & 0 & 0 & 0 & 137 & 118 & 139 & 32 & 80 & 90 & 8 & 82 & 105 & 16 & 99 & 112 & 96 & 113 & 133 & 58 & 97 & 129 & 132 & 27 & 75 \\
\hline 23 & & & & & & & & & & & & & 21 & 50 & 55 & 3 & 44 & $F$ & 54 & 16 & $G$ & 46 & 23 & 115 \\
\hline 24 & & & & & & & & & & & & & 101 & 60 & 79 & 95 & 90 & 84 & 112 & 42 & 1 & 17 & 12 & 117 \\
\hline 25 & & & & & & & & & & & & & 123 & 93 & 77 & 5 & 137 & 14 & 132 & 80 & 128 & 135 & 59 & 76 \\
\hline 26 & & & & & & & & & & & & & 92 & 33 & 39 & 62 & 134 & 9 & 36 & 18 & 66 & 98 & 86 & 97 \\
\hline 27 & & & & & & & & & & & & & 24 & 104 & 43 & 131 & 8 & 70 & 31 & 99 & 88 & 124 & 133 & 37 \\
\hline 28 & & & & & & & & & & & & & 85 & 41 & 122 & 7 & 82 & 53 & 74 & 111 & 71 & 100 & 49 & 126 \\
\hline 29 & & & & & & & & & & & & & 130 & 91 & 15 & $\mathrm{H}$ & 105 & 38 & 116 & 109 & 102 & 45 & 26 & 75 \\
\hline 30 & & & & & & & & & & & & & 29 & 27 & 22 & 78 & 25 & 13 & 48 & 2 & 28 & 19 & 73 & 127 \\
\hline 31 & & & & & & & & & & & & & 113 & 6 & 47 & 103 & 69 & 67 & 30 & 121 & 72 & 65 & 40 & 96 \\
\hline 32 & & & & & & & & & & & & & 0 & 0 & 0 & 0 & 58 & 81 & 52 & 83 & 107 & 139 & 61 & 68 \\
\hline 33 & & & & & & & & & & & & & 0 & 0 & 0 & 0 & 0 & 0 & 0 & 0 & 0 & 0 & 0 & 0 \\
\hline
\end{tabular}

keterangan: pohon atau individu asal jamur ganoderma yang diuji inkompatibilitas somatik

Gambar 8. Peta Kebun Benih F1 $A$. auriculiformis di Wonogiri, Jawa Tengah dan individu asal jamur ganoderma yang diuji somatik inkompatibilitas 
Pada gambar 8 dapat dilihat bahwa jamur-jamur ganoderma yang diuji inkompatibilitas somatik berasal dari beberapa pohon ada yang letaknya berdekatan dan berjauhan. Namun demikian hasil yang ditunjukkan semua pasangan isolat baik yang berdekatan maupun berjauhan adalah reaksi inkompatibel yang ditandai terbentuknya zona jarang, garis demarkasi, dinding dengan atau tidak disertai dengan pigmentasi. 36 pasangan isolat terdiri dari 8 pasangan sendiri dengan nilai skoring 0 (kompatibel), 14 pasangan isolat dengan nilai skor 1(inkompatibel lemah / inkompatibel tanpa pigmentasi) dan 13 lainnya dengan nilai skoring 2 (inkompatibel kuat / inkompatibel dengan pigmentasi).

Berdasarkan data hasil uji inkompatibilitas somatik, semua pasangan isolat yang berbeda menunjukkkan reaksi inkompatibel. Hasil tersebut mengidentifikasikan adanya variasi genetik diantara jamur ganoderma yang menyerang kebun benih $A$. auriculiformis $\mathrm{F} 1 \mathrm{di}$ Wonogiri, Jawa Tengah. Menurut Pilotti (2001) reaksi inkompatibilitas menunjukkan bahwa jamur tidak berasal dari klon genetik yang sama. Jamur ganoderma di kebun benih A. auriculiformis F1 di Wonogiri, Jawa Tengah memiliki tingkat keragaman genetik yang tinggi. Berdasarkan data hasil uji inkompatibilitas somatik dapat diindikasikan bahwa penyebaran penyakit busuk akar di kebun benih generasi pertama A. auriculiformis di Wonogiri, Jawa tengah tidak hanya terjadi melalui kontak akar tetapi melalui sebaran basidiospora. Menurut Pilotti et. al (2003) dan Nusaibah et. al (2010) sebaran jamur Ganoderma boninense yang menyerang kelapa sawit juga terjadi melalui basidiospora dan kontak akar. Penelitian Nusaibah et. al (2010), inkompatibilitas somatik mengidentifikasikan perbedaan genetik diantara isolat jamur ganoderma. Mekanisme inkompatibilitas somatik dilakukan dengan mencegah terjadinya anastomosis dan penolakan miselia. Hasil yang ditunjukkan adanya pembentukan garis demarkasi yang mengidentifikasikan adanya variasi genetik pada 4 species yaitu $G$. boninense, G. zonatum, G. miniatocinctum dan G. tornatum. Variasi genetik tidak hanya terjadi antar species bahkan juga terjadi dalam satu species.

Reaksi inkompatibilitas somatik terjadi pada seluruh uji pasangan antar dua isolat yang berbeda pohon. Hal tersebut 
menunjukkan bahwa jamur Ganoderma yang menginfeksi masing-masing pohon mempunyai variasi genetik yang berbeda tidak berasal dari klon genetik yang sama. Menurut Puspitasari dan Rimbawanto (2010) Keragaman genetik yang terjadi dalam satu spesies ini terjadi karena adanya persebaran basidiospora yang berasal dari tubuh buah yang terbentuk pada batang bawah tanaman maupun tunggak bekas tanaman yang telah terinfeksi busuk akar oleh jamur ganoderma. Adanya sisa-sisa tunggak kayu yang telah terinfeksi busuk akar oleh jamur ganoderma dari tanaman sebelumnya dapat menjadi sumber inokulum. Miselium jamur akan membentuk tubuh buah yang menghasilkan basidiospora jika menemukan substrat yang tepat, sehingga tubuh buah akan terbentuk pada tunggak-tunggak kayu yang tertinggal dalam areal tanaman. Spora akan menempel dan membentuk koloni miselium pada sisa tunggak kayu yang ada dan akan menular ke pohon yang lain melalui kontak akar. Pola persebaran penyakit busuk akar dapat digunakan untuk menentukan cara pengendalian busuk akar. Pola persebaran melalui persebaran spora jamur Ganoderma sp dapat dilakukan dengan membersihkan tunggak-tunggak yang tersisa di areal pertanaman, sehingga tidak akan ada substrat yang tepat bagi pertumbuhan jamur tersebut. Lokasi dengan keragaman populasi yang tinggi lebih sulit dikendalikan karena setiap individu yang berbeda akan menunjukkan respon yang berbeda.

Inkompatibilitas somatik dalam basidiomycetes adalah penolakan miselia yang berlainan genetik yang berfungsi untuk menjaga agar dalam suatu individu tidak terjadi perubahan genetik. Somatik inkompatibilitas mengatur penolakan dan pengakuan alel-alel atau gen-gen yang sesuai dan tidak sesuai yang mengikuti pembentukan sel tubuh dalam sebuah grup organisme. Somatik inkompatibilitas sangat berperan penting dalam konsep individual pada jamur. Somatik inkompatibilitas merupakan sebuah sistem untuk memelihara identitas individu (Worall, 1997 dan Lind et. al., 2007 ).

\section{KESIMPULAN}

Hasil uji inkompatibilitas somatik jamur ganoderma yang menyerang kebun benih F1 A. auriculiformis di Wonogiri, Jawa Tengah menunjukkan reaksi kompatibel pada seluruh pasangan sendiri (self pairing) dan reaksi inkompatibel pada seluruh pasangan 
isolat yang berbeda. Reaksi inkompatibel ditunjukkan dengan terbentuknya zona jarang, garis batas, dinding yang disertai dengan atau tanpa pembentukan pigmen. Hasil ini menunjukkan bahawa jamur ganoderma yang menyerang kebun benih F1 A. auriculiformis di Wonogiri, Jawa Tengah memiliki keragaman genetik dan tidak berasal dari klon genetik yang sama. Hal ini mengindikasikan bahwa sebaran busuk akar di kebun benih F1 A. auriculiformis di Wonogiri, Jawa Tengah terjadi melalui kontak akar dan sebaran basidiospora

\section{UCAPAN TERIMA KASIH}

Penulis mengucapkan terima kasih kepada Kurniawati Tri W., mahasiswa Fakultas Biologi, Universitas Negeri Yogyakarta yang telah melaksanakan praktek kerja lapangan dan membantu pelaksanaan penelitian uji inkompatibilitas somatik. Penulis juga mengucapkan terima kasih kepada Desy Puspitasari dan Ibu Margiyanti atas bantuannya dalam kegiatan penelitian ini.

\section{DAFTAR PUSTAKA}

Bina Produksi Kehutanan (Forestry Business Development). Satistik Kehutanan 2010. hhttp://www.scribd.com/doc/88508089/ STATISTIK-KEHUTANAN-2010

Fukuda, M., Ohno, S. and Kato, M. 2003. Genetics Variation in Cultivated Strains of Agaricus blazei. Mycoscience. 44:431-436

Golani, G.D. 2006. Pembangunan Hutan Tanaman di Indonesia dan Ancaman Terhadap Kelangsungannya. ACIAR Proceedings No. 124. Heart Rot and Root Rot in Tropical Acacia Plantations. Proceedings of a Workshop in Yogyakarta, Indonesia, 7-9 February 2006.

Guler, P. 2008. Somatic Incompatibility in Agaricus bitorquis (Quell.)Sacc. African Jurnal of Biotechnology. Vol. 7(3): 276-281

Hood, I.A. 2006. The Mycology of the Basidiomycetes . ACIAR Proceedings No. 124. Heart Rot and Root Rot in Tropical Acacia Plantations. Proceedings of a Workshop in Yogyakarta, Indonesia, 7-9 February 2006.

Latifah, Z and Ho. Y.W. 2005. Morphological Characteristics and Somatic Incompatibility of Ganoderma from Infected Oil Palm from Three Island Estates. Malaysian Journal of Microbiolgy. Vol 1 (2): 46-52

Li, L., Fan, X., Liu, W., Xiao, Y., and Biang, Y. 2011. Comparative Analysis on the Diversity Auricularia auricula-judae by Psychological Characteristics, Somatic Incompatibility and TRAF Fingerprinting. World J. Microbiol Biotechnol. 27: 20812093

Lind, M., Stenlid, J. and Olson, A. 2007. Genetics and QTL Mapping of Somatic Incompatibility and Intraspecific Interactions in The Basidiomycete Heterobasidion annosum s.l. Fungal Genetics and Biology. Vol. 44. P.1242-1251

Malik, M. and Vilgalys, R. 1999. Somatic incompatibility in Fungi. Population and Community Biology Series. Vol. 25. P. 123138

Nusaibah, S. A; Rajinder, S and Idris, A. S. 2010. Somatic Incompatibility and AFLP Analyses of Four Species Ganoderma Isolated from Oil Palm. Jurnal of Oil Palm Research. Vol. 22. P 814-821

Old, K.M; Lee, S.S, Sharma, J.K, and Yuan, Z.Q. 2000. A Manual Diseases of Tropical Acacias in Australia, South-East Asia and India. Center for International Forestry Research.

Pilotti, C.A. 2001. Genetics of Ganoderma spp. Associated with Oil Palm in Papua, New 
Guinea. Ph.D. Thesis. Department of Botany University of Queesland, Australia

Pilotti, C. A., Sanderson, F. R, Aitken, E.A.B. 2003. Genetic Structure of Population of Ganoderma boninense on Oil Palm. Plant Pathology. 52: 455-463

Puspitasari, D. dan Rimbawanto, A. 2010. Uji Somatik Inkompatibilitas Ganoderma philippii untuk Mengetahui Pola Sebaran Penyakit Busuk Akar pada Tanaman Acacia mangium dalam Jurnal Pemuliaan Tanaman Hutan. Yogyakarta : BBPBPTH Yogyakarta. Vol. 4. No.1, Juli 2010 hal: 49-61

Sahashi, N., Akiba, M., Ishihara, M., Miyazaki, K., and Seki, S. 2010. Distribution of Genets of Cylindribasidium argenteum in a River Valley Forest as Determined by Somatic Incompatibility and the Significance of Basiodiospores fot its Dispersal. Mycoll progress. 9: 425-449

Sebrana, C., Nuti, M.P., and Giovanneti, M. 2007. Self-anastomosing Ability and Vegetative
Incompatibility of Tuber Borchii Isolates. Mychorriza. 17:667-675

Semangun, H. 1991. Penyakit-penyakit Tanaman Perkebunan di Indonesia. Yogyakarta : Gadjah Mada University Press

Seo, G. S dan Kirk, P. M. 2000. Ganodermataceae, Nomenclature and Classification dalam Ganoderma Disease of Perennial Crops (eds. J. Flood, R. D. Bridge \& M. Holderness) CAB International 2000

Suwandi, Hamidson, H., and Naito, S. 2004. Distribution of Rigidiporus lignosus genotypes in a Rubber Plantation as Revealed by Somatic Incompatibility. Mycoscience. 45: 72-75

Triwaluyo, T.H., dan Anggraeni, I. 2000. Hama dan Penyakit Hutan. Diktat Standar Diklat Wirawana (Forest Ranger). Pusdiklat Kehutanan dan Perkebunan. Bogor.

Worral, J.J. 1997. Somatic Incompatibility in Basidiomycetes. Mycologia. 89 (1): 24-36 